\title{
Article \\ Development of a Distributed Mathematical Model and Control System for Reducing Pollution Risk in Mineral Water Aquifer Systems
}

\author{
Alexander V. Martirosyan *, Yury V. Ilyushin and Olga V. Afanaseva
}

check for

updates

Citation: Martirosyan, A.V.; Ilyushin, Y.V.; Afanaseva, O.V. Development of a Distributed Mathematical Model and Control System for Reducing

Pollution Risk in Mineral Water

Aquifer Systems. Water 2022, 14, 151. https://doi.org/10.3390/w14020151

Academic Editors: Maria Giovanna Tanda, Ilaria Butera, Andrea Zanini and Marco D'Oria

Received: 22 November 2021

Accepted: 4 January 2022

Published: 7 January 2022

Publisher's Note: MDPI stays neutral with regard to jurisdictional claims in published maps and institutional affiliations.

Copyright: (c) 2022 by the authors. Licensee MDPI, Basel, Switzerland. This article is an open access article distributed under the terms and conditions of the Creative Commons Attribution (CC BY) license (https:// creativecommons.org/licenses/by/ $4.0 /)$.
Department of System Analysis and Control, Saint Petersburg Mining University, 199106 Saint Petersburg, Russia; ilyushin_yuv@pers.spmi.ru (Y.V.I.); Afanaseva_OV@pers.spmi.ru (O.V.A.)

* Correspondence: martirosyan320@gmail.com

\begin{abstract}
The article is devoted to the problem of the growing need of the mineral water fields exploitation process automation. The implementation of control systems and mathematical modeling methods can significantly reduce the fields' structural integrity violation and pollution of aquifers risks. This research is especially relevant for the fields with difficult conditions of mineral waters occurrence, since the insufficient accuracy of determining the fields' operating mode parameters can lead to a severe incident. The article describes a distributed mathematical model developed from the geo-filtration equation. Based on this model, a new method for assessing the mutual influence of the fields, the production of which is carried out from one aquifer, is presented. For a more detailed study of the operating mode parameters influence on the object a physical model of the reservoir was developed. The using of Arduino sensors and the developed software allows us to construct a $3 \mathrm{D}$ graph of the input action and its response at the different points of the object as temperature distribution. The simulation results make it possible to use the proposed model for the automatic control system synthesis.
\end{abstract}

Keywords: mineral water field; mathematical model; system analysis; modeling; control; sensors

\section{Introduction}

Currently, the extraction of mineral resources is significant not only for the welfare of the Russian Federation [1], but also plays an important role in the world economy [2,3]. One of the main types of recoverable raw materials is raw materials with rheological properties. These types of raw materials include oil, water resources, etc. [4]. Most of the mineral water fields has difficult conditions for the occurrence of fluid in the reservoir. Extraction from that kind of fields is complicated by a huge number of factors affecting the state of the reservoir $[5,6]$. In the view of the greatest study, the fields of the Caucasian mineral waters $(\mathrm{CMW})$ region where the large volumes of mineral waters with a unique chemical composition are extracted were chosen as a test object. The chemical compositions of the most important to save CMW region's mineral waters are shown in the Table 1 . Under the influence of the constant intensive exploitation, the state of the hydrolithosphere of this region is deteriorating. In addition to the operation process, the general condition of the fields is influenced by such natural and man-made factors as: high wear and tear of the city sewage system, communal and engineering infrastructure, an extensive fleet of vehicles, chaotic buildings, etc. The combination of the presented factors slowly changes the conditions of occurrence of groundwater [7]. This leads to local emergencies, as a result of which their gradual pollution occurs. Hydromineral resources are an important component of a regional development, and some types of mineral waters have a unique chemical composition that has no analogues in the world [3]. 
Table 1. The chemical compositions of CMW region's mineral waters.

\begin{tabular}{|c|c|c|c|c|c|c|c|c|}
\hline \multirow{3}{*}{$\begin{array}{l}\text { Water } \\
\text { Name }\end{array}$} & \multirow{3}{*}{$\begin{array}{l}\text { Mineralization } \\
\mathrm{g} / \mathrm{dm}^{3}\end{array}$} & \multicolumn{6}{|c|}{ Main Ionic Composition } & \multirow{3}{*}{$\begin{array}{l}\text { Bioactive } \\
\text { Agents }\end{array}$} \\
\hline & & \multicolumn{3}{|c|}{ Anions, $\mathrm{mg} / \mathrm{dm}^{3}$} & \multicolumn{3}{|c|}{ Cations, $\mathrm{mg} / \mathrm{dm}^{3}$} & \\
\hline & & $\mathrm{HCO}_{3}{ }^{-}$ & $\mathrm{SO}_{4}{ }^{2-}$ & $\mathrm{Cl}^{-}$ & $\mathrm{Ca}^{2+}$ & $\mathrm{Mg}^{2+}$ & $\left(\mathrm{Na}^{+}+\mathrm{K}^{+}\right)$ & \\
\hline Narzan & $2.0-3.5$ & $1000-1700$ & $250-500$ & 50-200 & $200-500$ & $50-150$ & $50-250$ & $\begin{array}{c}\mathrm{CO}_{2} \\
1000-2500\end{array}$ \\
\hline $\begin{array}{l}\text { Dolomitic } \\
\text { Narzan }\end{array}$ & $4.0-4.5$ & $2000-2300$ & $600-800$ & $250-350$ & $650-700$ & $100-180$ & $300-400$ & $\begin{array}{c}\mathrm{CO}_{2} \\
2000-2300\end{array}$ \\
\hline $\begin{array}{l}\text { Sulphatic } \\
\text { Narzan }\end{array}$ & $5.0-5.5$ & $2300-2500$ & $\begin{array}{l}1400- \\
1600\end{array}$ & $<50$ & $700-800$ & $200-400$ & $200-300$ & $\begin{array}{c}\mathrm{CO}_{2} \\
2000-2300\end{array}$ \\
\hline Essentuki 4 & $7.0-10.0$ & $3400-4800$ & $<25$ & $\begin{array}{l}1300- \\
2000\end{array}$ & $<150$ & $<100$ & $2000-3000$ & $\begin{array}{c}\mathrm{H}_{3} \mathrm{BO}_{3} \\
30-60 \\
\mathrm{CO}_{2} \\
500-1800\end{array}$ \\
\hline Essentuki 17 & $10.0-14.0$ & $5000-7200$ & $<150$ & $\begin{array}{l}1200- \\
2200\end{array}$ & $<150$ & $<150$ & $2700-3900$ & $\begin{array}{c}\mathrm{H}_{3} \mathrm{BO}_{3} \\
30-80 \\
\mathrm{CO}_{2} \\
500-1200\end{array}$ \\
\hline
\end{tabular}

All of the above determines the necessity of the methods for monitoring the fields operation improving, since a serious accident at each of them can become an economic and environmental disaster for the region. As a possible solution of the problem, the using of the methods of mathematical modeling and the organization of automatic control of the mineral water extraction process is proposed [8].

\section{Problem Statement}

The existing automation systems for the well operations technological processes control are based on typical hydrogeological models $[9,10]$. Two types of models are most often used: hydrodynamic and hydraulic models [11,12]. The proposed solution has no analogues in the domestic market in the following parameters:

1. Possibility of considering the spatial distribution of the object (field);

2. Modeling a complex of interconnected hydrogeological objects;

3. Ability to control the parameters of the operating mode of a group of hydrogeological objects.

Mathematical models are developed, automatic control systems (ACS) are introduced, which help to ensure the required quality of the technological process (TP) $[13,14]$.

Mathematical modeling is one of the relatively universal ways to visualize what is happening in the reservoir before its development, i.e., at rest or in the initial state, as well as during its operation. The task of mathematical modeling of a field is to visualize all processes, and since the simplest way of information perception for a person is visual perception, therefore, a mathematical model of a reservoir is able to partially simplify a person's work with the development and operation of a field [5]. Absolutely adequate is the fact that it is impossible to build a universal mathematical model of the reservoir, since each field is unique. However, it is possible to build a mathematical model that would be adaptive and capable of evolution $[15,16]$.

The adaptive model is beneficial to use in the development of any reservoir. Several parameters change, and the mathematical model becomes clear and adequate for a new field.

A spatially distributed mathematical model is more visual, since these models reflects the change in a certain parameter not only depending on its location in space, but also reflect its change in time [17,18].

Model of the object is acting as automated control system's mathematical support. The algorithm of a control system and control object intercommunion is given on the Figure 1. 

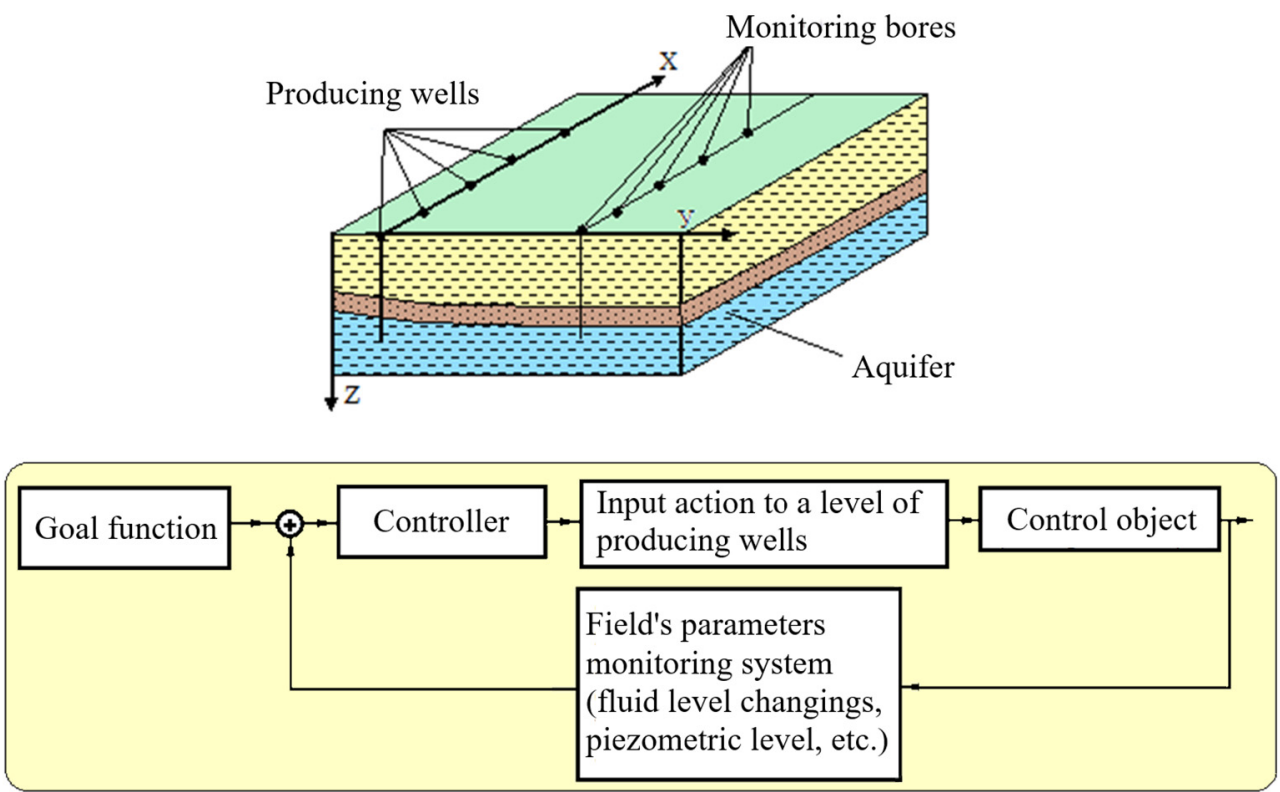

Figure 1. Conceptual model of the mineral water field control process.

At first, with using of a groundwater inflow testing information and the results of mathematical modeling the set point of the fluid level decreasing in monitoring bores is defining. Then, using the obtained data, controller calculates the input action value. After the control object reacts to the input action, the sensors can scan the main hydrodynamic parameters and the received data goes into the feedback-control loop, where the set value is compared with the obtained and the closed chain repeats.

\section{Methods}

\subsection{Method Description}

Analysis of modern research has made it possible to determine a set of effective methods for modeling hydrogeological objects, which are most often used to solve problems in this subject area $[3,5]$. As a result of the presented methods effectiveness analysis for the further research, the method of a mathematical description of the hydrogeological object in the form of a three-dimensional geo-filtration model was chosen. The experiment carried out on the prototype of the hydrogeological object model showed the admissible convergence values of the real data with the model ones. Accordingly, the developed model can adequately reflect the nature and intensity of the hydrodynamic processes of the field and can be used for the further research [18]. The proposed method makes it possible to ensure a sufficient degree of a model and real data convergence in the process of a mineral water field hydrogeological processes modeling. The technique applies to mineral water fields of I, II, III and IV groups of structural complexity.

According to the Guidelines on Alignment of Russian minerals reporting standards and the Committee for Mineral Reserves International Reporting Standards (CRIRSCO) the complexities of the field's geological structure are divided into the following groups:

1. First group. Deposits with a simple geological structure containing large or mediumsized bodies of minerals, which can be characterized by the stable thickness and internal structure, consistent quality of minerals and uniform distribution of the main valuable components.

2. Second group. Deposits with a complex geological structure containing large and medium-sized bodies with disturbed bedding, which can be characterized by unstable thickness and uneven distribution of the main valuable components.

3. Third group. Deposits with a very complex geological structure containing medium and small-sized bodies of minerals with intensively disturbed occurrence, which can 
be characterized by very variable thickness and internal structure, and a very uneven distribution of the main valuable components.

4. Fourth group. Deposits with a small, less often medium-sized bodies containing extremely disturbed bedding, which can be characterized by sharp variability of thickness and internal structure, extremely uneven quality of the mineral [18].

All hydrogeological calculations are based on the mathematical physics differential equations using, including the calculations of water permeability parameters. These parameters values are based on pumping data from wells and can provide that the natural environment is stable and filtration processes are schematized [19].

Schematization is carried out according to a number of natural factors: the hydrodynamic regime of the reservoir, the nature of its structure and boundary conditions in the section and plan. In addition, in the design scheme, it is necessary to consider the nature of the aquifer opening by wells [20].

According to the hydrodynamic regime, aquifers are divided into two main types: pressurized and non-pressurized.

For the model experiment, proposed in this paper, the following tools are used:

1. Delphi 7 software package;

2. Software package for modeling hydrodynamic processes developed up to GOST R $57,700.2$

3. Software package for modeling parameters of an open-loop control system developed up to GOST 24.104-85;

4. A software package for modeling the parameters of a closed-loop control system developed up to GOST 24.104-85;

5. A software package for modeling the spatial heterogeneity of the field strata hydrogeological structure developed up to GOST R 57,700.2 [21].

The mathematical model of the object describes the hydrodynamic processes flow nature in the field. The result of the input action is the distribution of the fluid level changing in a simulated formation [22]. The model can be considered as stable if, during the simulation, the system reaches a steady state in a time correlated with the real one, and the steady state level would not change during the entire calculation. Successful pilot simulation confirms the robustness of the model and the computational scheme [23].

After confirming the stability of the model by means of data obtained through experimental filtration works, the mathematical model is supplemented with data on tectonic changes or disruptions in the reservoir layers [24]. To reflect structural changes and disturbances in the reservoirs, the flow coefficient $b$ is determined by the spatial distribution in the reservoir (at each sampling point).

The overflow coefficient is calculated by the formula (Equation (1)):

$$
b=\sqrt{\frac{T \cdot m}{k}}
$$

where $T$ - some average value of the transmissibility of aquifers, $m$-thickness of lowpermeable layers, $k$-filtration coefficient.

The main criterion for the modeling results quality is the correspondence between the model and retrospective data on the decrease in the fluid level in the reservoir at a given production volume [25]. In the case, when the simulation accuracy is 70-85\% (depending on the complexity of the object and the task), the reliability of the developed mathematical model can be confirmed [26,27].

To improve the low modeling accuracy, the following factors, which can cause changes in the head (level) of groundwater, must be considered:

1. Hydrogeological conditions (lithological structure of water-bearing soils, feeding characteristics and conditions at the boundaries of the tested layer);

2. Groundwater regime (features of the pressure fluctuations nature-levels and the influence on these fluctuations of various disturbing sources, including technogenic); 
3. Technological conditions for testing, the data of which are used to check the accuracy of modeling (fluctuations in flow rate and pressure during pumping) [28].

Taking these factors into account, gives an opportunity to correct the design scheme and achieve a higher modeling accuracy for future control synthesis [29].

During the process of mathematical model of real nature object development, researchers are frequently face the lack of data problems. It is not always possible to receive the full report of groundwater inflow testing result. For mineral water fields with complicated conditions of mineral water occurrence it is impossible to receive this data, because in this case, the fields can be examined only in exploitation area. Even when researchers have a minimum required amount of information, it becomes a problem to provide a suitable level of model adequacy. To solve this problem the experimental installation, which can imitate the section of the mineral water field is proposed. Using different types of sensors and agents gives an opportunity to model a large amount of different input actions and explore the reactions of the object. In this paper the prototype of proposed installation, which can imitate the pressure difference in layer during the process of exploitation, is given.

\subsection{Development of the "Reservoir" Layout}

For research, a "layer" model of reservoir was created. In a cube-shaped container with the side of $14 \mathrm{~cm}$, the sand with fossils (small stones), a limestone layer, mineral water and clay in layers were placed.

At the first stage of development, it is necessary to decide on the sensors, which would be used. Because the measured parameter of the formation in the study is temperature, a digital temperature sensor DS18B20, which meets all the requirements, was selected. This sensor is a full-fledged thermometer that can measure temperature in the range from $-55^{\circ} \mathrm{C}$ to $+125^{\circ} \mathrm{C}$. Each sensor was assigned its own unique 64-bit address, which allows to provide the temperature value accurately determination from required point of the formation. The DS18B20 sensor operates with an accuracy of $\pm 0.5^{\circ} \mathrm{C}$. The sensor connection approach allows the connection of a whole group of sensors (up to 264) to a one line.

The study uses nine DS18B20 temperature sensors. Figure 2 shows an assembled connection diagram of nine sensors, which makes it easy to move the sensors in space independently of the circuit board.

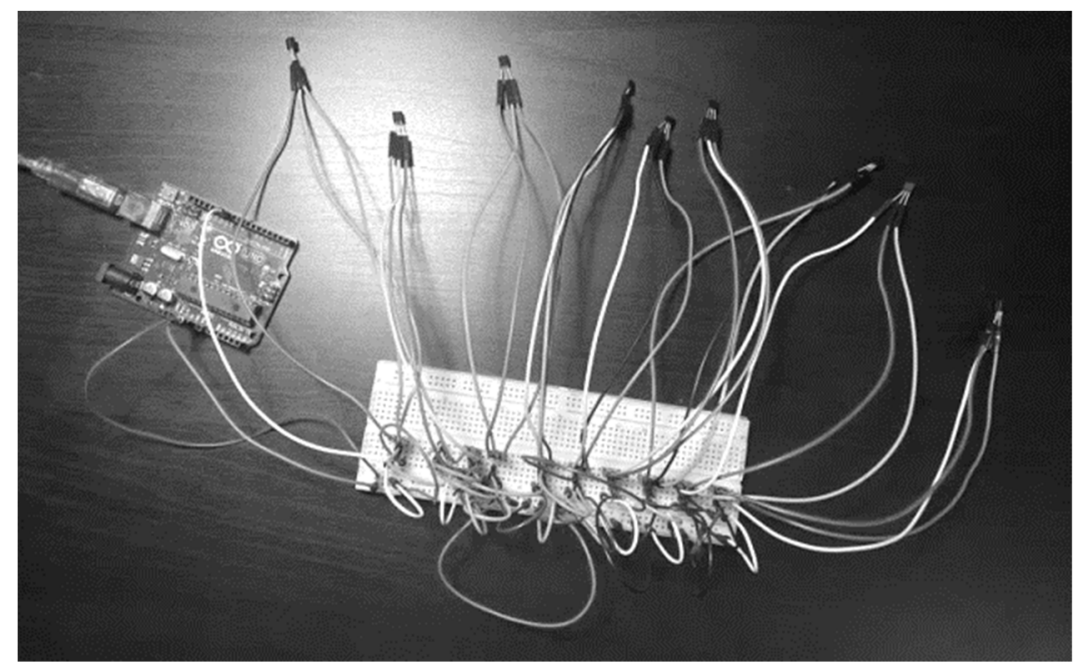

Figure 2. Device with DS18B20 sensors.

After physically connecting the sensors and working with them, it is necessary to use an Arduino IDE software (version 1.8.6), as well as the OneWire and Dallas Temperature libraries. As a programming language and environment, the Delphi and Embarcadero RAD Studio had been chosen. Then the algorithm for obtaining information about the 
temperature from the sketch must be developed. However, before determining the temperature which sensor will show the corresponding value, i.e., it is necessary to determine the address of each sensor, and its location in the circuit, so that the information about each point temperature could be obtained correctly.

The next stage was the development of a software module that records temperature data and its changes into a database (DB) and builds a spatially distributed mathematical model in the form of a 3D graph. It allows to analyze what is happening in terms of values, to consider the changes that have occurred over a certain period of time. In general, the database will store measurement times and temperatures (in ${ }^{\circ} \mathrm{C}$ ) at nine points of an object at every point in time. Temperature data type-numeric (field size-double with floating point), since in order to the fact, that the two decimal places accuracy will be enough to observe the temperature changing.

Moreover, each temperature value is classified as Txy in order to know exactly where a given point is located on the layer ( $x$ is responsible for the location of the point along the $\mathrm{x}$ coordinate, $\mathrm{y}$, respectively, along the $\mathrm{y}$ coordinate). The coordinate $\mathrm{z}$ leaves out of account because the only one layer of the reservoir formation is proposed. Consideration of one layer is enough for the created layout. In future, the additional sensors and layers can be added to improve the model.

Additionally, the database, which can store data on the measurement time and temperature values at specified points, was developed. It was necessary to develop a software module, which could give an opportunity to receive an information from sensors coming through the COM port, process it, record readings in the database and build in real time a 3D graph of temperature values at reservoir points. The final version of the program consists of the follows system components:

1. DBGrid (for the "temperature" table displaying);

2. DBNavigator (for table entries managing);

3. ADOConnection (for the communication with the database);

4. ADOQwery;

5. ComPortDriver;

6. Timer;

7. DataSource.

The direct processing takes time, and it becomes necessary to make sure that there are no failures due to time mismatches. A timer component that will be responsible for filling the table «temperature» can be added up.

To prevent the possible time displacement errors during the equation process the Timer component was added. A Timer component would control the table "temperature" filling process, while an additional condition of Edit would control filling data accuracy. The procedure fills the table «temperature» with data, which is transmitting from sensors via the communication ( $\mathrm{COM}$ ) port. There was no direct connection with the database, so this connection had been written in the program code. The result of this algorithm gives values for a $3 \mathrm{D}$ diagram of temperature spreading trends.

\section{Development of an Experimental Reservoir's Distributed Mathematical Model}

It was assumed that the reservoir is an ideal three-dimensional object, the view of which is shown in Figure 3.

Lx, Ly, Lz-geometric parameters of the object; S1, S2, S3, S4, S5, S6-face identifiers.

Initial conditions: $\mathrm{Lx}=0.06 \mathrm{~m}$., $\mathrm{Ly}=0.06 \mathrm{~m}$., $\mathrm{Lz}=0.06 \mathrm{~m}$. It could be assumed that the temperature on the supply circuit remains constant, i.e., boundary conditions on all sides are boundary conditions of the first kind and are denoted as « $0 »$, and the time interval (time step) $\mathrm{d} \tau=1 \mathrm{~s}$. Initial data are presented in Table 2 . 


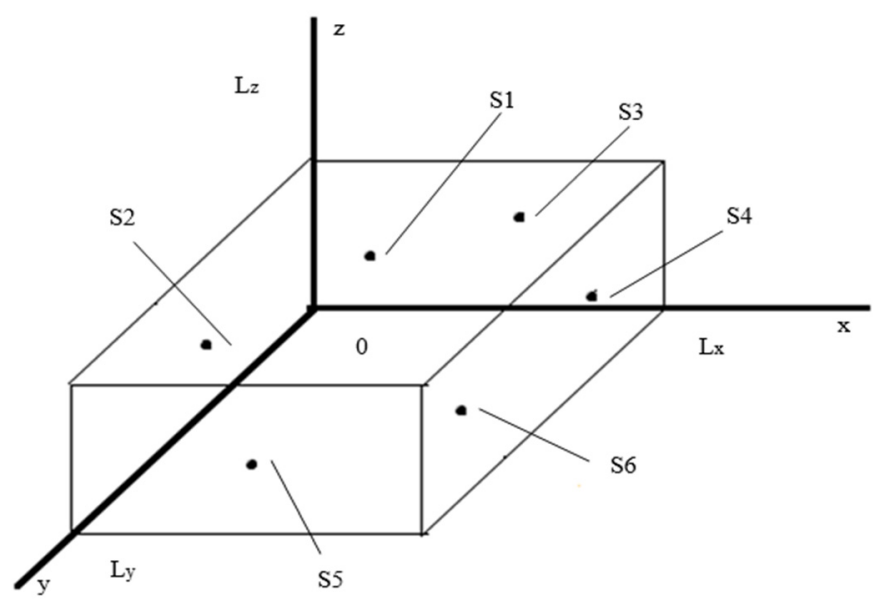

Figure 3. Reservoir model.

Table 2. Modeling Parameters.

\begin{tabular}{cccccccccc}
\hline $\mathbf{L X}, \mathbf{m}$ & $\mathbf{L Y}, \mathbf{m}$ & $\mathbf{L Z}, \mathbf{m}$ & $\partial, \mathbf{t ~ s}$. & $\mathbf{S 1}$ & $\mathbf{S 2}$ & $\mathbf{S 3}$ & $\mathbf{S 4}$ & $\mathbf{S 5}$ & S6 \\
\hline 0.03 & 0.03 & 0.01 & 1 & 0 & 0 & 0 & 0 & 0 & 0 \\
\hline
\end{tabular}

The main group of parameters, which allows the assessing of the field state at a given moment of time, as well as predicting its state after a certain period of time, includes temperature, pressure, permeability, reservoir properties of rocks, etc. Temperature, pressure and filtration coefficient are the main parameters of fluid movement in the reservoir. With a change in temperature, a change in pressure occurs, and, consequently, the movement of fluid in the reservoir and the well changes [30]. In this study, the parameter used for 3D modeling is temperature.

The choice of the proposed method is due to the following factors:

1. The proposed method takes into account the interstratal interactions of aquifer;

2. The proposed method gives a possibility of a three-dimensional model of the field mathematical description;

3. The proposed method provides a sufficiently high accuracy of the hydrodynamic processes' reflection for a given experiment;

4. The proposed method was successfully tested at one of the fields in the region under consideration [3].

The mathematical model of the reservoir as a distributed object is represented by the following equations [2]:

$$
\begin{aligned}
\frac{\partial T(x, y, z, t)}{\partial t} & =a \cdot\left(\frac{\partial^{2} T(x, y, z, t)}{\partial x^{2}}+\frac{\partial^{2} T(x, y, z, t)}{\partial y^{2}}+\frac{\partial^{2} T(x, y, z, t)}{\partial z^{2}}\right) \\
& 0<x<L_{x} ; 0<x<L_{y} ; 0<x<L_{z} ; t>0
\end{aligned}
$$

where $a$-thermal diffusivity, $\partial$-time sampling rate, $\partial x, \partial y, \partial z$-sampling steps in $x, y$ and $z$ coordinates, respectively, $t$-time, $\tau$-time step, $T(x, y, z, t)$-temperature at each point of the body at a time $t$. 
The boundary conditions under which Equation (2) should be solved can be written in the form of the planes faces ratios $\mathrm{P}$ :

$$
\left\{\begin{array}{l}
S 1: P\left(x, y, L_{z}\right)=0 ; 0<x<L_{x} ; 0<x<L_{y} ; t>0 \\
S 2: P(0, y, z)=0 ; 0<x<L_{y} ; 0<x<L_{z} ; t>0 \\
S 3: P(x, 0, z)=0 ; 0<x<L_{x} ; 0<x<L_{z} ; t>0 \\
S 4: P\left(L_{x}, y, z\right)=0 ; 0<x<L_{y} ; 0<x<L_{z} ; t>0 \\
S 5: P\left(x, L_{y}, z\right)=0 ; 0<x<L_{x} ; 0<x<L_{z} ; t>0 \\
S 6: P(x, y, 0)=0 ; 0<x<L_{x} ; 0<x<L_{y} ; t>0
\end{array}\right.
$$

This is one of the options for representing a spatially distributed mathematical model of a reservoir. In Equation (2), it remains to find $a$-the coefficient of thermal diffusivity. Equation (2) can be solved by the finite difference method [3]. The transformed equation can be represented as follows:

$$
\begin{gathered}
\frac{T_{i, j, k, l}-T_{i, j, k, l-1}}{\Delta t}=a\left(\frac{T_{i-1, j, k, l-1}-2 T_{i, j, k, l-1}+T_{i+1, j, k, l-1}}{\Delta x^{2}}+\right. \\
\left.+\frac{T_{i, j-1, k, l}-2 T_{i, j, k, l-1}+T_{i, j+1, k, l-1}}{\Delta y^{2}}+\frac{T_{i, j, k-1, l-1}-2 T_{i, j, k, l-1}+T_{i, j, k+1, l-1}}{\Delta z^{2}}\right) .
\end{gathered}
$$

One of the options when connecting sensors is to calculate the coefficients. The a-coefficient can be expressed from Equation (4) as follows:

$$
\begin{gathered}
a=\left(\frac{T_{i, j, k, l}-T_{i, j, k, l-1}}{\Delta t}\right) /\left(\frac{T_{i-1, j, k, l-1}-2 T_{i, j, k, l-1}+T_{i+1, j, k, l-1}}{\Delta x^{2}}+\right. \\
\left.+\frac{T_{i, j-1, k, l}-2 T_{i, j, k, l-1}+T_{i, j+1, k, l-1}}{\Delta y^{2}}+\frac{T_{i, j, k-1, l-1}-2 T_{i, j, k, l-1}+T_{i, j, k+1, l-1}}{\Delta z^{2}}\right) . \\
1<i<N_{x}=3 ; 1<j<N_{y}=3 ; 1<k<N_{z}=3 ; t>1,
\end{gathered}
$$

where $i$-sampling point number by $x, j$-sampling point number by $y, k$-sampling point number by $z, l$-sampling point number in time, $\Delta t$ - time sampling rate, $\Delta x$-sampling step by $x, \Delta y$-sampling step by $y, \Delta z$-sampling step by $z, N x, N y, N z$ - the number of sampling points in $x, y$ and $z$, respectively.

Let $n$ be the number of sampling points in $x, \mathrm{~m}$ is the number of sampling points in $y$, $r$ is the number of sampling points in $z$, then

$$
\Delta x=\frac{L_{x}}{n}=\frac{0.03}{3}=0.01 ; \Delta y=\frac{L_{y}}{n}=\frac{0.03}{3}=0.01 ; \Delta z=\frac{L_{z}}{n}=\frac{0.01}{3}=0.003 .
$$

Thus, it is possible to perform mathematical modeling of an object of complex shape, and now the experimental research can be performed.

\section{Results}

\subsection{Method Effectiveness Analysis}

The developed program can reliably reflect the dynamics and nature of hydrogeological processes occurring in the field [31]. Figure 4 shows the response of the system to a given decrease of the reservoir's fluid level in production well area.

For a given value of the input action equal to a decrease in the liquid level by $2 \mathrm{~m}$, the value obtained during the simulation is $1.92 \mathrm{~m}$, which confirms the adequacy of the developed model. Given accuracy results proofs the effectiveness of the proposed method, and gives an opportunity to use this model for interconnected objects. 


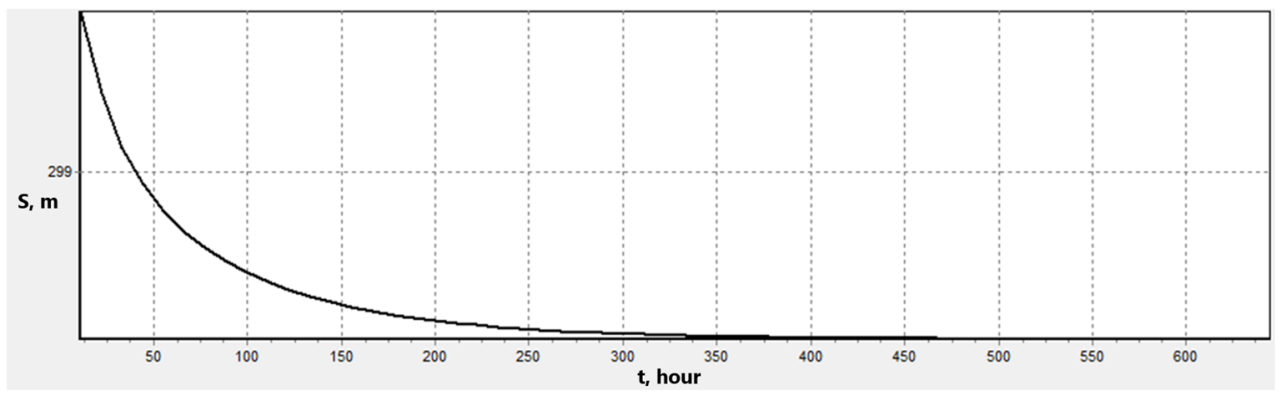

Figure 4. Graph of the fluid level lowering in the reservoir, $\mathrm{m}$.

In the classical method of geo-filtration modeling, the field is described as a single object, the external impact on which is specified by the boundary conditions, as well as the input and control actions. This concept does not imply the inclusion of one more object (system of equations) in the model. On the other hand, this method represents an object as a collection of wells located in a rectangular figure of finite dimensions. This level of abstraction makes it possible to represent the second object as a distant group of wells. Real geometric parameters of the object are used as the initial data of the model. The influence of another hydrogeological object can be represented as the input effect applied not to one of the wells groups in the field, but to a well located at a distance. Thus, it is possible to trace the dynamics of changes in the fluid level in the reservoir, representing two objects as two (or more) wells. To better match the model object to the real one, it is possible to change the model parameters at the sampling points between the wells under consideration, which will reflect the geological and hydrodynamic differences of the objects.

To test the proposed approach, the existing model was improved. Remote wells were introduced into the model to simulate an object located on the same aquifer. The object's response to a given input action (lowering the level by $2 \mathrm{~m}$ ) is shown in Figure 5 .

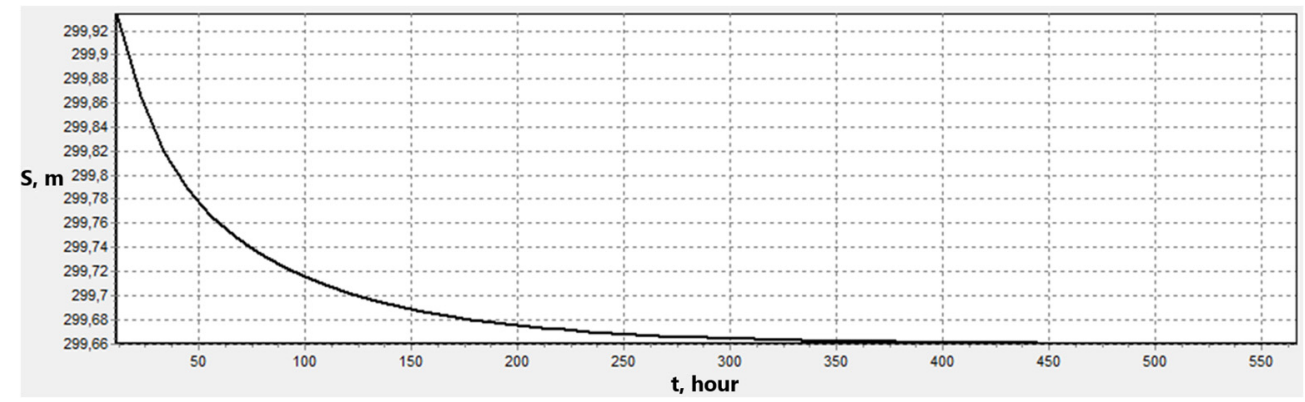

Figure 5. Graph of the fluid level lowering in the reservoir of the associated object, $\mathrm{m}$.

In the model example, the interconnected object is located at a distance of $15 \mathrm{~km}$ from the entry point. The resulting drop in level is $0.34 \mathrm{~m}$ or $17 \%$ of the target input, which is a significant change. Subsequent experiments made it possible to reveal the following patterns of hydrogeological objects mutual influence. With production within the maximum allowable volumes, a noticeable effect $(>5 \%)$ on the fluid level in the reservoir is observed at a distance of 5 to $15 \mathrm{~km}$. At a distance of 25 to $60 \mathrm{~km}$, the production mutual influence on the fluid level in the reservoir of the field located further downstream is $1-3 \%$. With an average production rate, such a value of the change in the fluid level in the reservoir can be neglected, but in the case of high intensity, it is this slight change in the level that can have a detrimental effect on the state of the mineral water field.

\subsection{Control System Synthesis Results}

The interaction and change of the temperature field must be considered in the development of the control system [32,33]. Only with a detailed calculation of the intensity of 
mutual influence and considering the results obtained when determining the permissible production volumes, the stability of the operation process and the structural integrity of the fields can be guaranteed [34,35]. As an experiment, the obtained data on the mutual influence of wells were used to correct the initial data of the control system [36,37]. The result of the synthesized control system operation is shown in Figure 6.

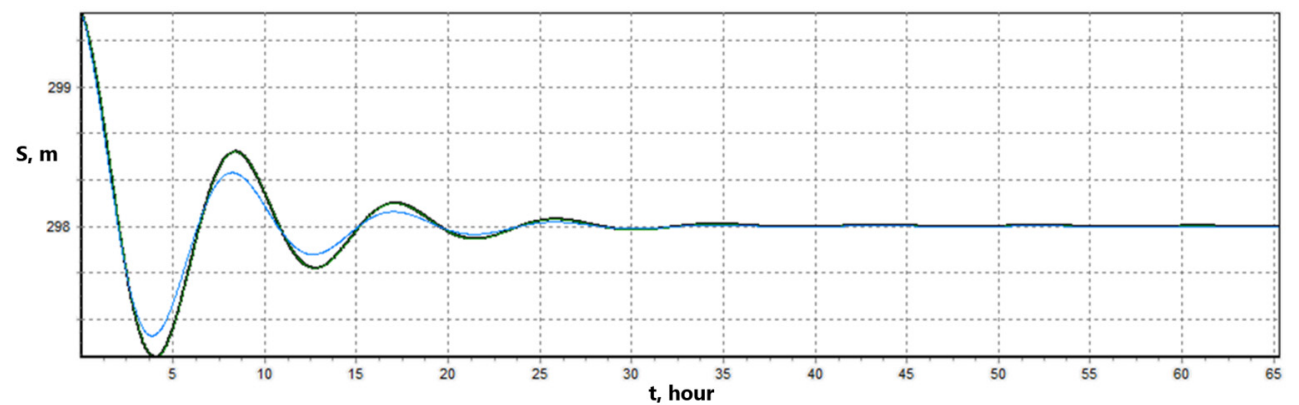

Figure 6. Result of the control system functioning at the set values.

Based on the experiment results, it can be affirmed that the using of this systems' class to solve the problem of automating the hydrogeological objects exploitation is effective. The implementation of control systems at enterprises producing from the same aquifer at different fields (Kislovodskoye/Nagutskoye, etc.) is a necessity. Difficult bedding conditions and the deteriorating condition of fields (subsidence of the upper impervious layers, formation of cracks, the risk of contamination by wastewater, etc.) necessitate continuous adjustment of parameters to maintain a stable operating mode. Thus, even in the case of a slight change in the hydrodynamic characteristics, an error may appear, and the established production volumes will become excessive, which will inevitably lead to an accident.

\subsection{Experimental Reservoir's Distributed Mathematical Model Result Analysis}

The main task of the software module development was to build a spatially distributed mathematical model of the reservoir in the form of a 3D graph. The image of 3D graph was obtained using the Plot3D component, which is free of charge and at free accessed.

The result of a spatially distributed mathematical model of a complex-shaped reservoir modeling is shown in Figure 7. Reservoir temperature changes do not occur until the development of this reservoir begins. This can be seen from the table of values in the window and the table of reservoir temperature values (sensor readings).

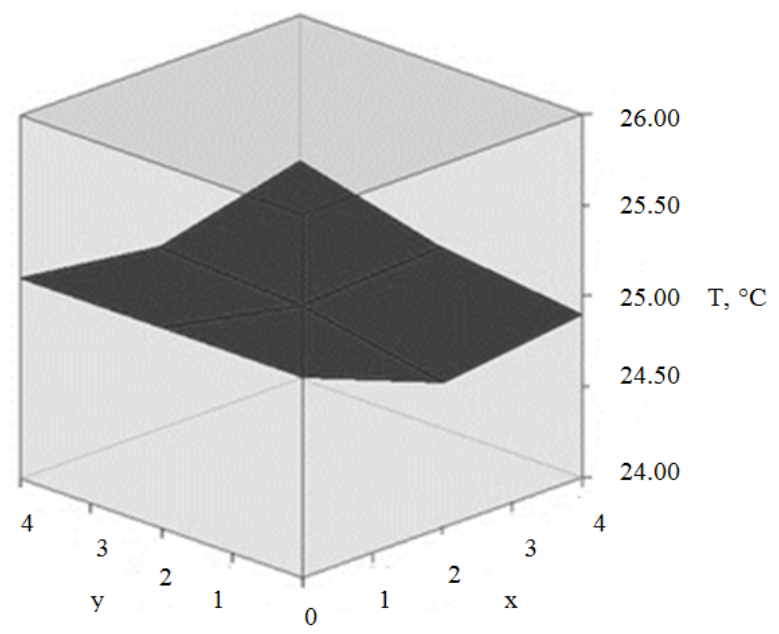

Figure 7. Graph of reservoir temperature distribution at a certain point in time. 
The developed model meets the specified number of requirements, such as adequacy, visibility, adaptability, and the ability to evolve.

The mathematical model is adequate because built according to the values of sensors that measure the temperature at the points of the real model. It is visual, because all changes that occur are displayed in such a way that a person sees these changes and is able to carry out an analysis based on them. The model is adaptive. This model, or rather the software module that outputs this model, can be used not only within this layout. The developed program that builds 3D graphics is capable of evolution, and accordingly the model too. In this case, it was considered to apply a configuration with nine connected sensors, which are located within one layer.

\section{Conclusions}

Currently, the number of the fields at the stage of declining production is increasing. In this regard, the question of the necessity of the fields' belonged to the stage of decollement development, as well as about increasing the output at the existing fields arises. The implementation of the control systems in enterprises producing from the same aquifer in different fields is a necessity. The presented method of the mineral water fields' mutual influence modeling, which are produced from one aquifer, is able to increase the accuracy of hydrodynamic processes' reflection, which will make it possible to achieve a more stable and safe operating mode. Difficult bedding conditions and the deteriorating condition of the fields (subsidence of the upper impervious layers, formation of cracks, the risk of contamination by wastewater, etc.) are force out to use continuous adjustment of parameters to maintain a stable operating mode. The consequences of changes (penetration of household and anthropogenic pollution into the exploited formations, destruction of the field's formations), which can lead to an incorrect operation mode, are irreversible.

Using and improvement of the proposed experimental installation is capable to receive an innovation success in the scientific research of the groundwater modeling area. At the initial stage, the developed model is able to reflect the structure of the field's reservoir segment. Even at the initial stage of research, the reaction of a model object is close to a real object. Improving this model by using different rocks, minerals capable of simulating the aquifers and watertight formations heterogeneity. A pressure chamber can be used to simulate the pressure in the reservoir, which will allow providing better-detailed study of hydrodynamic processes. The data and patterns resulting from the experiments can increase the level of knowledge of mineral water fields' modeling methods.

Practical results can be applied to solve problems of control processes automation for complex objects with distributed parameters. On the basis of theoretical studies, the development of a practical method will make it possible to analyze control systems in relation to a group of natural objects with a complex spatial structure and be used by companies producing mineral water (AO(JSC) "Narzan", etc.). The research results can also be applied in the oil and gas industry, provided that oil and gas fields are modeled based on the proposed methods.

At that moment, three areas of further research have been identified:

1. Application of sensitivity analysis methods to assess the impact of changes in the initial parameters of the model on the output characteristics.

2. Adaptation and scaling of the developed modeling methods for solving problems of the oil and gas industry.

Author Contributions: Conceptualization, Y.V.I. and A.V.M.; methodology, A.V.M.; software, Y.V.I.; validation, O.V.A.; formal analysis, Y.V.I.; investigation, O.V.A.; resources, Y.V.I.; data curation, O.V.A.; writing—original draft preparation, A.V.M.; writing—review and editing, Y.V.I., A.V.M. and O.V.A.; visualization, O.V.A.; supervision, O.V.A.; project administration, A.V.M.; funding acquisition, Y.V.I. All authors have read and agreed to the published version of the manuscript. 
Funding: The research was performed at the expense of a subsidy for the state assignment in the field of scientific activity for 2021 № FSRW-2020-001 (Development and System Analysis of a Mineral Water Field's Exploitation Parameters Control Systems). Submitted research was carried out at the Saint Petersburg Mining University.

Data Availability Statement: Not applicable.

Conflicts of Interest: The authors declare no conflict of interest.

\section{References}

1. Resniova, E.; Ponomarenko, T. Sustainable Development of the Energy Sector in a Country Deficient in Mineral Resources: The case of the Republic of Moldova. Sustainability 2021, 13, 3261. [CrossRef]

2. Ponomarenko, T.; Nevskaya, M.; Jonek-Kowalska, I. Mineral Resource Depletion Assessment: Alternatives, problems, results. Sustainability 2021, 13, 862. [CrossRef]

3. Pershin, I.M.; Malkov, A.V.; Pomelyayko, I.S. Design of a distributed debit management network of operating wells of fields of the CMW region. In Proceedings of the 3rd International Conference on Futuristic Trends in Network and Communication Technologies, Taganrog, Russia, 14-16 October 2020; pp. 317-328.

4. Vasilev, Y.; Cherepovitsyn, A.; Tsvetkova, A.; Komendantova, N. Promoting Public Awareness of Carbon Capture and Storage Technologies in the Russian Federation: A system of educational activities. Energies 2021, 14, 1408. [CrossRef]

5. Pershin, I.M.; Kukharova, T.V.; Tsapleva, V.V. Designing of Distributed Systems of Hydrolithosphere Processes Parameters Control for the Efficient Extraction of Hydromineral Raw Materials. J. Phys. Conf. Ser. 2021, 1728, 012017. [CrossRef]

6. Pomelyaiko, I.S.; Malkov, A.V. Quality Problems of Surface Water and Groundwater at the Health Resorts in the Regions of Caucasian Mineral Waters and Ways to Their Solution. Water Resour. 2019, 46, 214-225. [CrossRef]

7. Hirsch, R.M.; Slack, J.R.; Smith, R.A. Techniques of Trend Analysis for Monthly Water Quality Data. Water Resour. Res. 1982, 18, 107-121. [CrossRef]

8. Hombeck, R.; Keskin, P. The evolving impact of the Ogallala Aquifer-Agricultural adaptation to groundwater and climate. US Natl. Bur. Econ. Res. Work. Pap. 2011, 39, 17625.

9. Iverson, R.M. Landslide Triggering by Rain Infiltration. Water Resour. Res. 2000, 36, 1897-1910. [CrossRef]

10. Jourabchi, P.; Lin, G.K.-C. Modeling Vapor Migration for Estimating the Time to Reach Steady State Conditions. Groundw. Monit. Remediat. 2021, 41, 25-32. [CrossRef]

11. Zolotov, O.I.; Ilyushina, A.N.; Novozhilov, I.M. Spatially distributed system for monitoring of fields technical condition in mineral resources sector. In Proceedings of the XXIV International Conference on Soft Computing and Measurements, Saint-Petersburg, Russia, 26-28 May 2021; pp. 93-95.

12. Xing, L.; Wen, C.; Liu, Z.; Su, H.; Cai, J. Event-Triggered Adaptive Control for a Class of Uncertain Nonlinear Systems. IEEE Trans. Fuzzy Syst. 2017, 62, 2071-2076. [CrossRef]

13. Feng, G. A Survey on Analysis and Design of Model-Based Fuzzy Control Systems. IEEE Trans. Fuzzy Syst. 2006, 14, 676-697. [CrossRef]

14. Hou, Z.; Xiong, S. On Model-Free Adaptive Control and Its Stability Analysis. IEEE Trans. Autom. Control 2019, 64, 4555-4569. [CrossRef]

15. Hu, X.; Li, Y.; Che, X.; Hou, Z. Event-Based Adaptive Fuzzy Asymptotic Tracking Control of Uncertain Nonlinear Systems. IEEE Trans. Fuzzy Syst. 2021, 29, 3003-3013.

16. Golubev, V.O.; Litvinova, T.E. Dynamic simulation of industrial-scale gibbsite crystallization circuit. J. Min. Inst. 2021, 247, 88-101. [CrossRef]

17. Tavernini, D.; Metzler, M.; Gruber, P.; Sorniotti, A. Explicit Nonlinear Model Predictive Control for Electric Vehicle Traction Control. IEEE Trans. Control Syst. Technol. 2019, 27, 1438-1451. [CrossRef]

18. Guidelines on Alignment of Russian Minerals Reporting Standards and the CRIRSCO Template. Available online: https: //www.crirsco.com/docs/conversion_guidelines_final.pdf (accessed on 17 December 2021).

19. Federal Agency of Technical Control and Metrology. GOST 23278-78. Available online: http:/ / protect.gost.ru/document1.aspx? control=31\&baseC $=6 \&$ page $=0 \&$ month $=5 \&$ year $=2017 \&$ search $=23278 \& i d=188687$ (accessed on 15 November 2021).

20. Federal Agency of Technical Control and Metrology. GOST R 57700.2. Available online: http:/ / protect.gost.ru/document1.aspx? control=31\&baseC $=6 \&$ page $=4 \&$ month $=5 \&$ year $=2017 \&$ search $=\& i d=217662$ (accessed on 15 November 2021).

21. Dashko, R.E.; Romanov, I.S. Forecasting of Mining and Geological Processes Based on the Analysis of the Underground Space of the Kupol Field as a Multicomponent System. J. Min. Inst. 2021, 247, 20-32. [CrossRef]

22. Khabarov, N.; Smirnov, A.; Balkovič, J.; Skalský, R.; Folberth, C.; Van Der Velde, M.; Obersteiner, M. Heterogeneous Compute Clusters and Massive Environmental Simulations Based on the EPIC Model. Modelling 2020, 1, 215-224. [CrossRef]

23. Korotenko, V.A.; Grachev, S.I.; Kushakova, N.P.; Mulyavin, S.F. Assessment of the Influence of Water Saturation and Capillary Pressure Gradients on Size Formation Of Two-Phase Filtration Zone in Compressed Low-permeable Reservoir. J. Min. Inst. 2020, 245, 569-581. [CrossRef]

24. Reinecke, R.; Wachholz, A.; Mehl, S.; Foglia, L.; Niemann, C.; Döll, P. Importance of Spatial Resolution in Global Groundwater Modeling. Groundwater 2020, 58, 363-376. [CrossRef] 
25. Meshkov, A.A.; Kazanin, O.I.; Sidorenko, A.A. Improving the Efficiency of the Technology and Organization of the Longwall Face Move During the Intensive Flat-lying Coal Seams Mining at the Kuzbass Mines. J. Min. Inst. 2021, 249, 342-350. [CrossRef]

26. Kupfersberger, H.; Rock, G.; Draxler, J.C. Combining Groundwater Flow Modeling and Local Estimates of Extreme Groundwater Levels to Predict the Groundwater Surface with a Return Period of 100 Years. Geosciences 2020, 10, 373. [CrossRef]

27. Metzler, M.; Tavernini, D.; Gruber, P.; Sorniotti, A. On Prediction Model Fidelity in Explicit Nonlinear Model Predictive Vehicle Stability Control. IEEE Trans. Control Syst. Technol. 2021, 29, 1964-1980. [CrossRef]

28. Klizas, P. Geofiltration studies of clay at the future radioactive waste repository for Ignalina nuclear power plant. J. Environ. Eng. Landsc. Manag. 2021, 22, 219-225. [CrossRef]

29. Pashkevich, N.V.; Golovina, E.I. Topical issues of the management of extraction of underground waters on the territory of the Russian Federation. J. Min. Inst. 2014, 210, 99-107.

30. Takemura, J.; Yao, C.; Kusakabe, O. Development of a Fault Simulator for Soils under Large Vertical Stress in a Centrifuge. Int. J. Phys. Model. Geotech. 2020, 20, 118-131. [CrossRef]

31. Martirosyan, A.; Martirosyan, K. Quality improvement information technology for mineral water field's control. In Proceedings of the IEEE Conference on Quality Management, Transport and Information Security, Information Technologies, Nalchik, Russia, 4-11 October 2016; pp. 147-151.

32. Jensen, J.K.; Nilsson, B.; Engesgaard, P. Numerical Modeling of Nitrate Removal in Anoxic Groundwater during River Flooding of Riparian Zones. Groundwater 2021, 59, 866-877. [CrossRef] [PubMed]

33. Qin, H. Numerical groundwater modeling and scenario analysis of Beijing plain: Implications for sustainable groundwater management in a region with intense groundwater depletion. Environ. Earth Sci. 2021, 80, 499. [CrossRef]

34. Medici, G.; Smeraglia, L.; Torabi, A.; Botter, C. Review of Modeling Approaches to Groundwater Flow in Deformed Carbonate Aquifers. Groundwater 2021, 59, 334-351. [CrossRef]

35. Ou, G. Development of GUI Applications for Groundwater Modeling Using Python. Groundwater 2020, 58, 496-497. [CrossRef]

36. Ilyushina, A.N.; Novozhilov, I.M. Development of the automated temperature field control system with a pulsed heating source. In Proceedings of the III International Conference on Control in Technical Systems, Saint-Petersburg, Russia, 30 October-1 November 2019; pp. 160-163.

37. Cao, Z.; Niu, Y.; Lam, H.-K.; Zhao, J. Sliding Mode Control of Markovian Jump Fuzzy Systems: A Dynamic Event-Triggered Method. IEEE Trans. Fuzzy Syst. 2021, 29, 2902-2915. [CrossRef] 